\title{
Block Copolymers of Macrolactones/Small Lactones by a "Catalyst- Switch" Organocatalytic Strategy. Thermal Properties and Phase Behavior
}

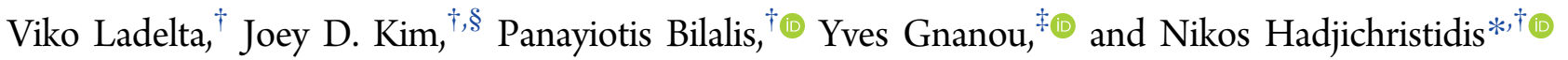 \\ ${ }^{\dagger}$ Physical Sciences and Engineering Division, KAUST Catalysis Center, Polymer Synthesis Laboratory, and ${ }^{\ddagger}$ Physical Sciences and \\ Engineering Division, King Abdullah University of Science and Technology (KAUST), Thuwal 23955, Saudi Arabia
}

\section{Supporting Information}

ABSTRACT: Poly(macrolactones) (PMLs) can be considered as biodegradable alternatives of polyethylene; however, controlling the ring-opening polymerization (ROP) of macrolactone (ML) monomers remains a challenge due to their low ring strain. To overcome this problem, phosphazene $\left(t-\mathrm{BuP}_{4}\right)$, a strong superbase, has to be used as catalyst. Unfortunately, the one-pot sequential block copolymerization of MLs with small lactones (SLs) is impossible since the high basicity of $t$ $\mathrm{BuP}_{4}$ promotes both intra- and intermolecular transesterification reactions, thus leading to random copolymers. By using ROP and the "catalyst-switch" strategy [benzyl alcohol, $t$ - $\mathrm{BuP}_{4} /$ neutralization with diphenyl phosphate $/\left(t\right.$ - $\left.\left.\mathrm{BuP}_{2}\right)\right]$, we were able to synthesize different well-defined PML- $b$-PSL block copolymers (MLs: dodecalactone, $\omega$-pentadecalactone, and $\omega$ hexadecalactone; SLs: $\delta$-valerolactone and $\varepsilon$-caprolactone). The thermal properties and the phase behavior of these block copolymers were studied by differential scanning calorimetry and X-ray diffraction spectroscopy. This study shows that the thermal properties and phase behavior of PMLs-b-PSLs are largely influenced by the PMLs block if PMLs components constitute the majority of the block copolymers.

\section{INTRODUCTION}

Aliphatic polyesters are important materials with a wide range of properties and applications. ${ }^{1-5}$ In particular, aliphatic polyesters derived from lactones have tunable mechanical and thermal properties, crystallinity, and are biocompatible/ biodegradable materials. ${ }^{6,7}$ Lactones can be prepared from cheap and renewable bio-based materials such as fatty acids., ${ }^{8,9}$ In addition, the current development of synthetic methodologies allows the synthesis of new copolymers of lactones with lactides, cyclic carbonates, and epoxides to afford novel biocompatible/biodegradable polymeric materials with diverse properties. $^{10}$

The ring-opening polymerization (ROP) of lactones is a versatile method to synthesize (co)polymers with controlled molecular parameters. ${ }^{11}$ ROP of small lactones (SLs $\leq 8$ membered rings) such as $\delta$-valerolactone (VL) and $\varepsilon$ caprolactone (CL) has been well studied, and ways have been developed leading to control polymerization. ${ }^{10,12,13}$ In contrast, for medium lactones and macrolactones (MLs) (ring size $>8$ ), it is more difficult to find the appropriate conditions for controlled ROP due to their low ring strain. Only a limited number of enzymes ${ }^{14-16}$ and catalysts, metal based ${ }^{14-17}$ or organocatalysts, ${ }^{18-21}$ are capable of promoting ROP of MLs to high conversion. In addition, attempts to prepare block copolymers of poly(macrolactones) and poly(small lactones) (PMLs-b-PSLs) with these catalysts have been unsuccessful.

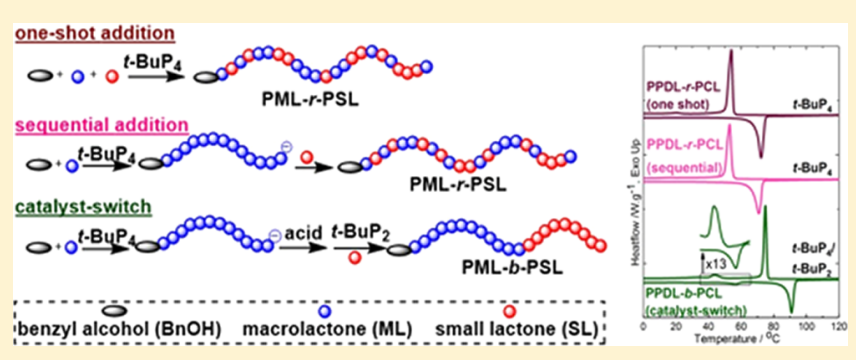

The ROP of $\omega$-pentadecalactone (PDL) with enzyme Candida antarctica lipase-B (CAL-B) resulted in high conversion but broad molecular weight distributions $\left(\bigoplus_{M}\right)^{22}$ The copolymerization of PDL with CL, by sequential monomer addition, catalyzed by the same enzyme, produced random structure instead of block due to rapid interchain transesterification. ${ }^{23}$ The aluminum-salen complex, known to be very active for the ROP of MLs, also produced random instead of block copolymers by sequential addition of MLs and SLs. ${ }^{24}$ Dove et al. reported the copolymerization of PDL with CL, VL, and $\eta$-caprylolactone using $\mathrm{Mg}(\mathrm{BHT})_{2}(\mathrm{THF})_{2}$ as catalyst, but no block copolymerization was described. ${ }^{25}$ Recently, a combination of $\mathrm{N}$-heterocyclic olefin/metal halide Lewis pair as dual catalysts system showed a rapid ROP of PDL. ${ }^{26}$ This system also was used to sequentially copolymerize PDL with $\mathrm{CL}, \mathrm{VL}$, and $\gamma$-butyrolactone, which again led to the formation of random copolymers. A bicyclic guanidine, 1,5,7-triazabicyclo[4.4.0]dec-5-ene (TBD), was reported as the first organic catalyst capable of promoting ROP of PDL. ${ }^{18}$ Attempts to prepare block copolymer by sequential addition of PDL and $\mathrm{CL}$ with the benzyl alcohol $(\mathrm{BnOH}) / \mathrm{TBD}$ initiating system were unsuccessful.

Received: January 22, 2018

Revised: March 2, 2018 
To the best of our knowledge, only zinc- and calcium-based complexes bearing ancillary ligands, reported by Duchateau et al., are capable of promoting the homopolymerization of PDL to high conversion and the subsequent copolymerization with CL to form semicrystalline PPDL- $b$-PCL (only one sample was reported, and the actual length of each block was not clarified). ${ }^{14}$ The structure of PPDL- $b$-PCL was confirmed by ${ }^{1} \mathrm{H}$ and ${ }^{13} \mathrm{C}$ NMR spectroscopies, and thermal properties were analyzed by differential scanning calorimetry (DSC). Moreover, block copolymers of PDL with $\varepsilon$-decalactone $(\varepsilon \mathrm{DL})$ were also prepared to study the effect of the amorphous P $\varepsilon \mathrm{DL}$ block (branch lactone) on the crystallization of the PPDL block. ${ }^{27}$ Nevertheless, block copolymers comprising both ML and SL blocks and prepared by an organic catalyst in one pot are still absent in the literature.

We recently reported a fast and living organocatalytic ROP of PDL and $\omega$-hexadecalactone (HDL) to high conversion catalyzed by a phosphazene superbase (PSB) 1-tert-butyl4,4,4-tris (dimethylamino)-2,2-bis [tris(dimethylamino)phosphoranylidenamino $]-2 \lambda^{5}, 4 \lambda^{5}$-catenadi(phosphazene) $(t$ $\left.\mathrm{BuP}_{4}, \mathrm{pK}_{\mathrm{a}, \mathrm{ACN}}=42.7\right){ }^{21}$ The ROP proceeds to high conversion under a wide range of conditions. Our group had also reported the controlled and living ROP of SLs promoted by a weaker PSB 1-tert-butyl-2,2,4,4,4-pentakis(dimethylamino)- $2 \lambda,{ }^{5} 4 \lambda^{5}$ catenadi(phosphazene) $\left(t-\mathrm{BuP}_{2}, \mathrm{pK}_{\mathrm{a}, \mathrm{ACN}}=33.5\right)$ with different initiators. $^{12} \mathrm{~A}$ one-pot sequential block copolymerization of epoxides and CL was successfully performed by a catalystswitch strategy from $t$ - $\mathrm{BuP}_{4}$ to an organic acid (diphenyl phosphate $\left.[\mathrm{DPP}], \mathrm{pK}_{\mathrm{a}, \mathrm{DMSO}}=3.88\right)$ or $t-\mathrm{BuP}_{2} \cdot{ }^{28-32}$ An alcohol initiator, activated by $t$ - $\mathrm{BuP}_{4}$ (suitable for polymerizing epoxides but not SLs), was used to promote the ROP of epoxides, followed by neutralization of the superbase with DPP. Subsequently, a weaker PSB, $t$ - $\mathrm{BuP}_{2}$ (suitable for polymerizing SLs but not epoxides), was added to promote ROP of SLs leading to well-defined polyepoxide-polyester block copolymers. These findings motivated us to employ similar catalystswitch methodology to prepare PMLs- $b$-PSLs.

Herein, we report the ROP of MLs (dodecanolactone [DDL], PDL, and $\mathrm{HDL}$ ) to high conversion with $t-\mathrm{BuP}_{4}$ as catalyst, the neutralization of $t-\mathrm{BuP}_{4}$ with $\mathrm{DPP}$, and the subsequent addition of $t-\mathrm{BuP}_{2}$ as second catalyst for the growth of the PSLs (VL and CL) block from the PMLs macroinitiator in one-pot. The formation of PMLs-b-PSLs was evidenced by ${ }^{13} \mathrm{C} \mathrm{NMR},{ }^{1} \mathrm{H} \mathrm{NMR}$, and high-temperature gel permeation chromatography (HT-GPC). Their thermal properties and phase behavior were analyzed using DSC, and the crystal structure was determined by X-ray diffraction (XRD) spectroscopy.

\section{EXPERIMENTAL SECTION}

Materials. Toluene (AnalaR NORMAPUR ACS, VWR International Chemicals) was dried first over calcium hydride $\left(\mathrm{CaH}_{2}, 95 \%\right.$, Sigma-Aldrich), then over polystyryllithium and distilled before use. DDL (98\%), PDL (>98\%), HDL (>98\%), CL (99\%), and VL (99\%) from Sigma-Aldrich were distilled twice over $\mathrm{CaH}_{2}$ under dynamic vacuum. $t-\mathrm{BuP}_{4}(0.8 \mathrm{M}$ solution in hexane $), t-\mathrm{BuP}_{2}(2 \mathrm{M}$ solution in THF), and benzoic acid (99.5\%) were purchased from Sigma-Aldrich and used as received. DPP (99\%, Sigma-Aldrich) was purified by dissolving it in benzene (anhydrous, 99.8\%, Sigma-Aldrich), followed by cryo-evaporation of benzene and drying under vacuum overnight. $\mathrm{BnOH}$ (99.8\%, Sigma-Aldrich) was distilled twice over $\mathrm{CaH}_{2}$ under vacuum. $\mathrm{BnOH}$, lactone monomers, DPP, and PSBs were stored under argon (Ar) in a glovebox (LABmaster ${ }^{\text {pro } S P, ~ M B r a u n, ~ G e r m a n y) . ~}$ Methanol (HiPerSolv CHROMANORM, VWR International Chem- icals) and 1,2,4-trichlorobenzene (TCB; $\geq 99 \%$, anhydrous, SigmaAldrich) were used as received.

Instrumentation. NMR measurements were performed at room temperature (rt) using a Bruker AVANCEDIII spectrometer operating at 500 or $950 \mathrm{MHz}$ in $\mathrm{CDCl}_{3} .{ }^{1} \mathrm{H}$ NMR spectra were used to calculate the number-average molecular weight $\left(M_{\mathrm{n}, \mathrm{NMR}}\right)$ of the polyesters by using the integrals of the characteristic signals from the end group and $\omega$-methylene protons of PMLs-PSLs. HT-GPC measurements were performed with a PL-GPC 220 high temperature chromatograph (Agilent Technologies) with one PLgel $5 \mu \mathrm{m}$ MIXED-C column. The column has a linear molecular weight operating range from 200 to $2000000 \mathrm{~g} \mathrm{~mol}^{-1}$ and high resolution. TCB was used as eluent at a flow rate of $1.0 \mathrm{~mL} \mathrm{~min}{ }^{-1}$ at $150{ }^{\circ} \mathrm{C}$. The instrument was calibrated with polystyrene (PS) standards. DSC measurements were performed with a Mettler Toledo DSC1/TC100 under air. The samples were first heated from rt to $120{ }^{\circ} \mathrm{C}$ in order to erase the thermal history, then cooled to $-20{ }^{\circ} \mathrm{C}$, and finally heated again to $120{ }^{\circ} \mathrm{C}$ at a heating/ cooling rate of $10{ }^{\circ} \mathrm{C} \mathrm{min}^{-1}$. This cycle was repeated until constant melting and cooling temperatures $\left(T_{\mathrm{m}}\right.$ and $\left.T_{\mathrm{c}}\right)$ were recorded. XRD spectra were obtained from XRD Bruker D8 Advance using $\mathrm{Cu} \mathrm{K} \alpha$ radiation. The sample for $\mathrm{XRD}$ measurements was deposited on a glass plate with an approximate size $1.5 \mathrm{~cm} \times 1 \mathrm{~cm}$, preannealed at $120^{\circ} \mathrm{C}$ for $10 \mathrm{~min}$, and cooled down to rt with a cooling rate $10{ }^{\circ} \mathrm{C} \mathrm{min}^{-1}$.

Synthetic Procedure. Synthesis of PPDL-r-PCL by a One-Shot Monomer Addition (Table 1, Entry 2). In a glovebox under Ar atmosphere, $2.3 \mu \mathrm{L}$ of $\mathrm{BnOH}(23 \mu \mathrm{mol}), 28 \mu \mathrm{L}(23 \mu \mathrm{mol})$ of $t-\mathrm{BuP}_{4}$ solution, and $3 \mathrm{~mL}$ of dry toluene were charged into a round-bottom flask. The flask was quickly sealed by a Rotaflo stopcock, removed from the glovebox, and stirred for $10 \mathrm{~min}$ in a preheated oil bath at 80 ${ }^{\circ} \mathrm{C}$. Then, a mixture of $0.54 \mathrm{~g}$ of PDL $(2.3 \mathrm{mmol})$ and $0.25 \mathrm{~mL}$ of CL $(2.3 \mathrm{mmol})$ in $2 \mathrm{~mL}$ of dry toluene was added to the initiator solution. The copolymerization of PDL and CL was performed for $3 \mathrm{~h}$, and monomer conversion was monitored by ${ }^{1} \mathrm{H}$ NMR analysis. After PDL and $\mathrm{CL}$ reached high conversion, the reaction was quenched by adding benzoic acid/ $\mathrm{CHCl}_{3}(10 \mathrm{vol} \%)$ and cooled to rt. One drop of crude product was withdrawn and dissolved in $\mathrm{CDCl}_{3}$ to check the monomer conversion by ${ }^{1} \mathrm{H}$ NMR. The rest of the reaction mixture was precipitated in $500 \mathrm{~mL}$ of methanol, filtered by glass filter, and dried in vacuo at $45^{\circ} \mathrm{C}$ for $12 \mathrm{~h} .{ }^{1} \mathrm{H} \mathrm{NMR}\left(950 \mathrm{MHz}, \mathrm{CDCl}_{3}, 298 \mathrm{~K}\right) \delta / \mathrm{ppm}=$ $7.30-7.37$ (aromatic protons on the end group) $\delta 5.11(\mathrm{~s}, 2 \mathrm{H} ; \mathrm{C}=$ $\left.\mathrm{OOCH}_{2} \mathrm{Ar}\right), 4.05\left(\mathrm{~m}, \mathrm{CH}_{2} \mathrm{OC}=\mathrm{O}, 4 \mathrm{H}\right.$; for PPDL and PCL $), 2.29(\mathrm{t}, J$ $\left.=7.6 \mathrm{~Hz},-\mathrm{CH}_{2} \mathrm{C}=\mathrm{OO}(\mathrm{PCL})\right), 2.27\left(\mathrm{t}, J=7.5 \mathrm{~Hz},-\mathrm{CH}_{2} \mathrm{C}=\mathrm{OO}\right.$ (PPDL)), 1.64 (m, $\left.\mathrm{CH}_{2} \mathrm{CH}_{2} \mathrm{OC}=\mathrm{O} \mathrm{PCL}\right), 1.60$ (m, $\mathrm{CH}_{2} \mathrm{CH}_{2} \mathrm{OC}=$ O PPDL), $1.22-1.40 \mathrm{ppm}$ (all remaining hydrogens). $M_{\mathrm{n}, \mathrm{NMR}}=22.2$ $\mathrm{kg} \mathrm{mol}^{-1}$ (PPDL); $M_{\mathrm{n}, \mathrm{NMR}}=11.9 \mathrm{~kg} \mathrm{~mol}^{-1}(\mathrm{PCL})$.

Typical Polymerization Procedure for the Synthesis of PMLs-bPSLs (Table 2, Entry 1). In a glovebox under Ar atmosphere, $4.6 \mu \mathrm{L}$ of $\mathrm{BnOH}(45 \mu \mathrm{mol}), 56 \mu \mathrm{L}(45 \mu \mathrm{mol})$ of $t-\mathrm{BuP}_{4}$ solution, and $2.5 \mathrm{~mL}$ of dry toluene were charged into a round-bottom flask. The flask was quickly sealed by a Rotaflo stopcock, removed from the glovebox, and stirred for $10 \mathrm{~min}$ in a preheated oil bath at $80^{\circ} \mathrm{C}$. Then, $1.1 \mathrm{~g}$ of PDL $(4.5 \mathrm{mmol})$ in $2 \mathrm{~mL}$ of dry toluene was added to the initiator solution. The homopolymerization of PDL was performed for $2 \mathrm{~h}$, and conversion was monitored by ${ }^{1} \mathrm{H}$ NMR analysis. The reaction mixture was neutralized by the addition of $113 \mu \mathrm{L}$ of DPP $(45 \mu \mathrm{mol})$ at $80{ }^{\circ} \mathrm{C}$ and kept stirring for $30 \mathrm{~min} .118 \mu \mathrm{L}(225 \mu \mathrm{mol})$ of $t-\mathrm{BuP}_{2}$ solution was added. After $30 \mathrm{~min}, 0.49 \mathrm{~mL}(4.5 \mathrm{mmol})$ of $\mathrm{CL}$ was added to the polymerization mixture. After $\mathrm{CL}$ reached high conversion, the reaction was quenched by adding benzoic acid/ $\mathrm{CHCl}_{3}$ (10 vol \%) and cooled to rt. For all polymerization reactions, one drop of crude product was withdrawn and dissolved in $\mathrm{CDCl}_{3}$ to check the monomer conversion by ${ }^{1} \mathrm{H}$ NMR. The rest of the reaction mixture was precipitated in $500 \mathrm{~mL}$ of methanol, filtered by a glass filter, and dried in vacuo at $45{ }^{\circ} \mathrm{C}$ for $12 \mathrm{~h} .{ }^{1} \mathrm{H} \mathrm{NMR}\left(950 \mathrm{MHz}, \mathrm{CDCl}_{3}, 298 \mathrm{~K}\right) \delta /$ $\mathrm{ppm}=7.34$ (aromatic protons on the end group) $\delta 5.10(\mathrm{~s}, 2 \mathrm{H} ; \mathrm{C}=$ $\left.\mathrm{OOCH}_{2} \mathrm{Ar}\right), 4.05\left(\mathrm{~m}, \mathrm{CH}_{2} \mathrm{OC}=\mathrm{O}, 4 \mathrm{H}\right.$; for PPDL and PCL), $2.30(\mathrm{t}, J$ $\left.=7.6 \mathrm{~Hz},-\mathrm{CH}_{2} \mathrm{C}=\mathrm{OO}(\mathrm{PCL})\right), 2.28\left(\mathrm{t}, J=7.6 \mathrm{~Hz},-\mathrm{CH}_{2} \mathrm{C}=\mathrm{OO}\right.$ (PPDL)), $1.64\left(\mathrm{~m}, \mathrm{CH}_{2} \mathrm{CH}_{2} \mathrm{OC}=\mathrm{O}\right.$ PCL), $1.60\left(\mathrm{~m}, \mathrm{CH}_{2} \mathrm{CH}_{2} \mathrm{OC}=\right.$ O PPDL), $1.22-1.40 \mathrm{ppm}$ (all remaining hydrogens). $M_{\mathrm{n}, \mathrm{NMR}}=35.5$ $\mathrm{kg} \mathrm{mol}^{-1}(\mathrm{PPDL}) ; M_{\mathrm{n}, \mathrm{NMR}}=15.9 \mathrm{~kg} \mathrm{~mol}^{-1}(\mathrm{PCL})$. 

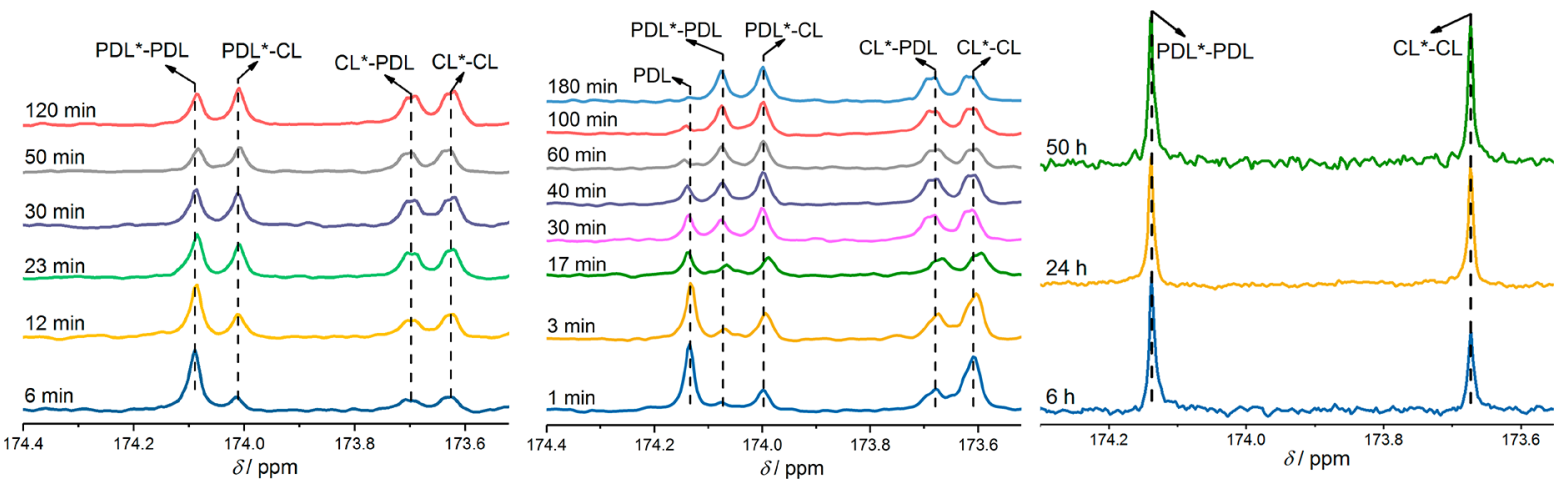

Figure 1. ${ }^{13} \mathrm{C}$ NMR spectra of copolymerization products of PDL and CL: sequential monomer addition (left), one-shot monomer addition (middle), and catalyst-switch strategy (right) $\left(\mathrm{CDCl}_{3}, \mathrm{rt}\right)$.

Table 1. RO Copolymerization of PDL and CL Catalyzed by PSBs with Different Method in Toluene at $80{ }^{\circ} \mathrm{C}^{a}$

\begin{tabular}{|c|c|c|c|c|c|c|c|c|c|}
\hline \multirow[b]{2}{*}{ entry } & \multirow[b]{2}{*}{ method } & \multirow[b]{2}{*}[\mathrm{PDL}]{$_{0} /[\mathrm{CL}]_{0} /[\mathrm{I}]_{0} /\left[\mathrm{P}_{4}\right] /\left[\mathrm{P}_{2}\right]$} & \multirow[b]{2}{*}{ time $(\mathrm{h})$} & \multicolumn{2}{|c|}{$\operatorname{conv}^{c}(\%)$} & \multicolumn{4}{|c|}{ dyads sequence distribution ${ }^{d}(\%)$} \\
\hline & & & & PDL & $\mathrm{CL}$ & $\mathrm{CL} *-\mathrm{CL}$ & $\mathrm{CL}^{*}-\mathrm{PDL}$ & $\mathrm{PDL}^{*}-\mathrm{PDL}$ & $\mathrm{PDL}^{*}-\mathrm{CL}$ \\
\hline 1 & sequential & $100 / 100 / 1 / 1 /-$ & 2 & 96 & 100 & 26.2 & 24.0 & 24.4 & 25.4 \\
\hline 2 & one-shot ${ }^{b}$ & $100 / 100 / 1 / 1 /-$ & 3 & 98 & 100 & 27.8 & 24.1 & 22.8 & 25.3 \\
\hline 3 & catalyst-switch & $100 / 100 / 1 / 1 / 5$ & 50 & 99 & 92 & 49.1 & 0 & 50.9 & 0 \\
\hline
\end{tabular}

${ }^{a}$ Polymerizations were performed under $\mathrm{Ar},[\mathrm{M}]_{0}=1 \mathrm{M}$. ${ }^{b}$ Total initial monomer concentration $=2 \mathrm{M}$. ${ }^{c}$ Conversions of PDL and CL were determined by $950 \mathrm{MHz}{ }^{1} \mathrm{H}$ NMR spectra of crude product from the integral of $\omega$-methylene protons of PDL, CL, and copolymers in $\mathrm{CDCl}$. ${ }^{d}$ Determined by $950 \mathrm{MHz}{ }^{13} \mathrm{C}$ NMR spectra of the isolated polymer from the carbonyl carbon resonance.

\section{Scheme 1. General Scheme for the Synthesis of PML-b-PSL by Catalyst-Switch Strategy}

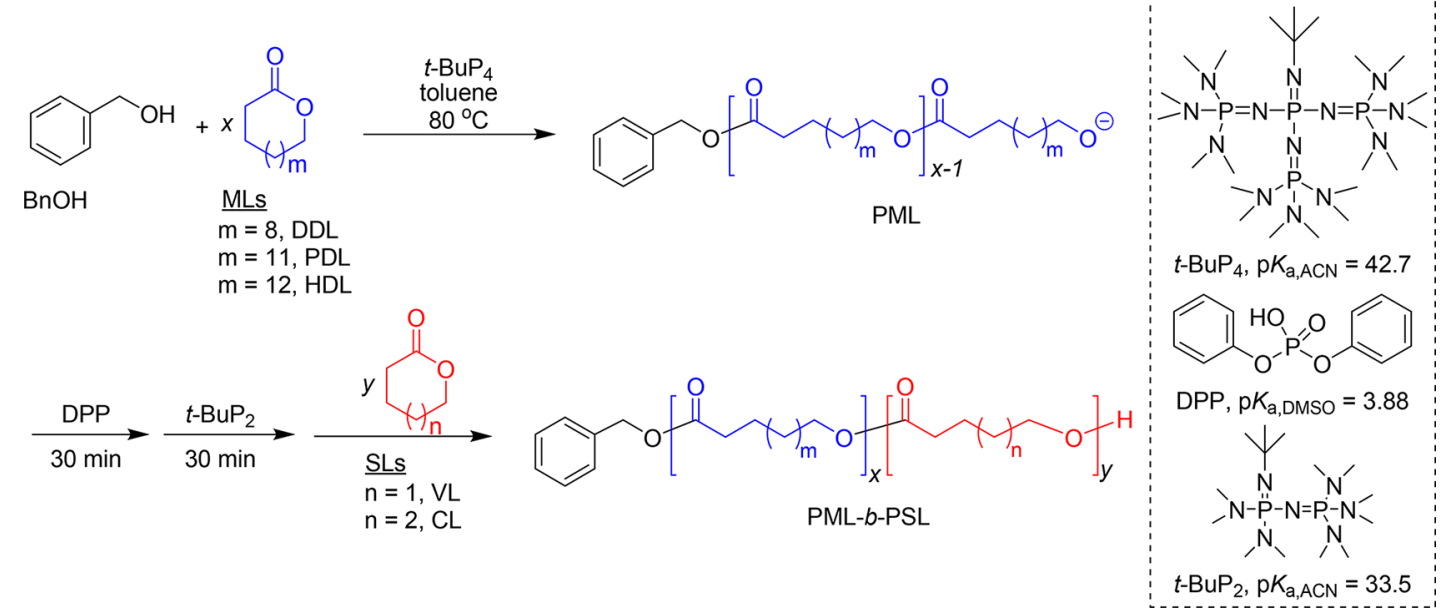

\section{RESULTS AND DISCUSSION}

The common method to prepare block copolymers by anionic ROP is via one-pot sequential monomer addition using a common catalyst. ${ }^{33}$ We employed this method to prepare PPDL- $b$-PCL with $\mathrm{BnOH}: t-\mathrm{BuP}_{4}: \mathrm{PDL}: \mathrm{CL}$ molar ratio of 1:1:100:100 (entry 1, Table 1 ). $\mathrm{BnOH}$ was mixed with $t$ $\mathrm{BuP}_{4}$ in toluene followed by the addition of PDL (dissolved in toluene) at $80{ }^{\circ} \mathrm{C}$. The conversion of PDL reached $96 \%$ in $2 \mathrm{~h}$. Subsequently, CL was added to the polymerization mixture, and the reaction was continued for $2 \mathrm{~h}$. Quantitative ${ }^{13} \mathrm{C}$ NMR spectrosopy was used to monitor the progress of the reaction as well as the microstructure of the polymer formed (Figure 1, left). The ${ }^{13} \mathrm{C}$ NMR spectra shown in Figure 1 (left) were taken from the reaction mixture after addition of $\mathrm{CL}$ to PPDL macroinitiator with $t$ - $\mathrm{BuP}_{4}$ as catalyst. The ${ }^{13} \mathrm{C}$ NMR spectrum revealed that at the early stage $(6 \mathrm{~min})$ of the ROP of $\mathrm{CL}$, the PDL*-PDL (asterisk represents the observed carbonyl

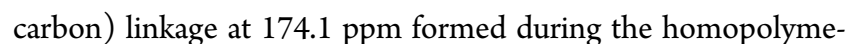
rization of PDL as the main peak and a small peak due to CL*-CL linkages (173.2 ppm). Two new peaks coming from $\mathrm{PDL}^{*}-\mathrm{CL}(174.0 \mathrm{ppm})$ and CL*-PDL (173.4 ppm) linkages were also observed representing the formation of a random structure. After $23 \mathrm{~min}$, the incorporation of $\mathrm{CL}$ to the copolymer increased significantly indicating the fast ROP of CL with $t-\mathrm{BuP}_{4}$, but the intensity of $\mathrm{PDL}^{*}-\mathrm{CL}$ and $\mathrm{CL}^{*}-\mathrm{PDL}$ linkages also increased. After $120 \mathrm{~min}$, the microstructure of the resulting polymer became fully random as shown by dyads sequence distribution of the isolated product (entry 1, Table 1). The final microstructure of the isolated polymer is similar to the copolymer prepared by one-shot addition of PDL and CL which exhibits a random distribution (Figure 1, middle, and entry 2, Table 1).

The overall observation suggests that both chain propagation and transesterification side reactions occurred during the 

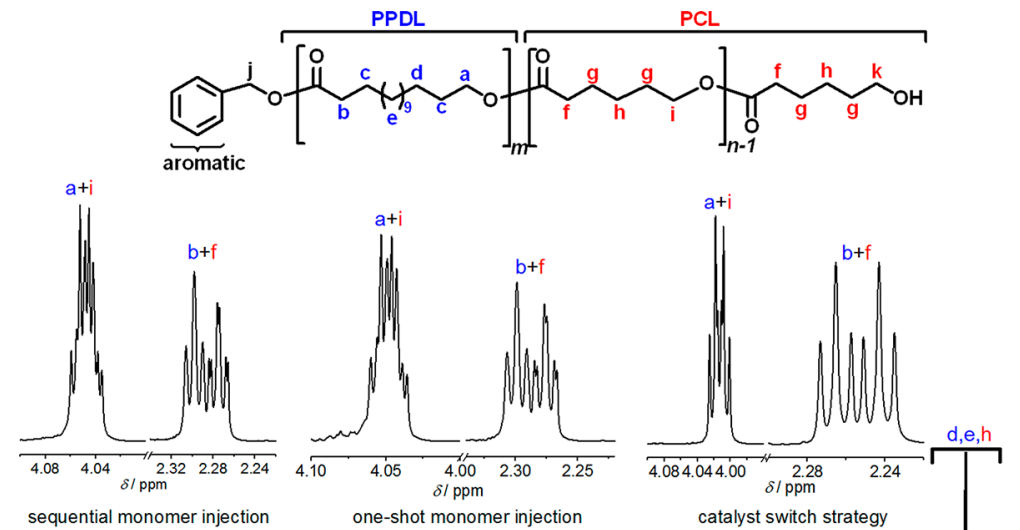

one-shot monomer injection

catalyst switch strategy

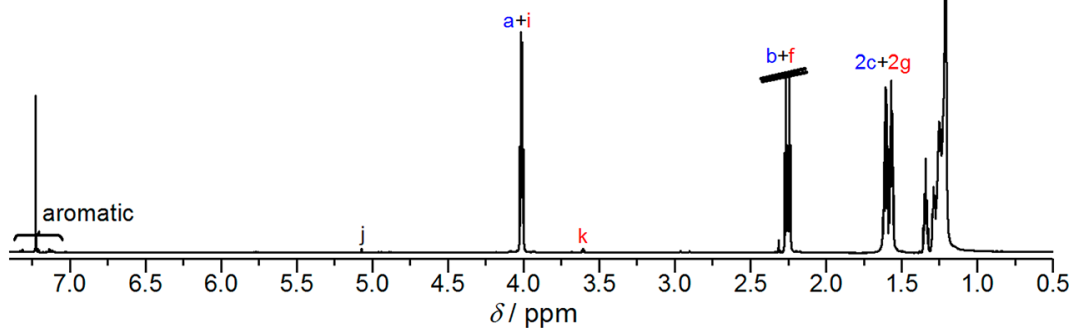

Figure 2. ${ }^{1} \mathrm{H}$ NMR spectra of PDL-CL copolymers prepared by sequential monomer addition, one-shot monomer addition, and catalyst-switch strategy $\left(950 \mathrm{MHz}, \mathrm{CDCl}_{3}, \mathrm{rt}\right)$.

Table 2. Block Copolymers of MLs and SLs Prepared by Catalyst-Switch Strategy ${ }^{a}$

\begin{tabular}{|c|c|c|c|c|c|c|c|c|}
\hline \multirow[b]{2}{*}{ entry } & \multirow[b]{2}{*}{ sample } & \multirow[b]{2}{*}[\mathrm{M}]{$_{0} /[\mathrm{I}]_{0} /\left[\mathrm{P}_{4}\right] /\left[\mathrm{P}_{2}\right]$} & \multirow[b]{2}{*}{ time $(\mathrm{h})$} & \multicolumn{2}{|c|}{$\operatorname{conv}^{b}(\%)$} & \multicolumn{2}{|c|}{$M_{\mathrm{n}, \mathrm{NMR}}{ }^{c}\left(\mathrm{~kg} \mathrm{~mol}^{-1}\right)$} & \multirow[b]{2}{*}{$\bigoplus_{M}^{d}$} \\
\hline & & & & $\mathrm{ML}$ & SL & ML & SL & \\
\hline 1 & PPDL- $b$-PCL & $200 / 1 / 1 / 5$ & 96 & 99 & 92 & 35.5 & 15.9 & 1.77 \\
\hline 2 & PPDL- $b$-PVL & $200 / 1 / 1 / 5$ & 74 & 99 & 95 & 27.1 & 8.8 & 1.85 \\
\hline 3 & PHDL- $b$-PCL & $200 / 1 / 1 / 5$ & 96 & 99 & 93 & 31.5 & 10.6 & 1.86 \\
\hline 4 & PHDL- $b$-PVL & $200 / 1 / 1 / 5$ & 74 & 99 & 96 & 65.9 & 17.4 & 1.92 \\
\hline 5 & PDDL- $b$-PCL & $200 / 1 / 1 / 5$ & 96 & 99 & 95 & 29.2 & 16.8 & 1.62 \\
\hline 6 & PDDL- $b$-PVL & $200 / 1 / 1 / 5$ & 74 & 99 & 98 & 39.3 & 19.2 & 1.70 \\
\hline 7 & $\mathrm{PPDL}_{50}-b-\mathrm{PCL}_{400}{ }^{e}$ & $230 / 1 / 1 / 5$ & 96 & 99 & 85 & 14.7 & 52.3 & 2.20 \\
\hline 8 & PCL & $100 / 1 / 0 / 5$ & 48 & & 83 & & 10.9 & 1.16 \\
\hline 9 & PVL & $100 / 1 / 0 / 5$ & 12 & & 96 & & 7.9 & 1.19 \\
\hline 10 & PPDL & $100 / 1 / 1 / 0$ & 2 & 99 & & 35.0 & & 1.77 \\
\hline 11 & PHDL & $100 / 1 / 1 / 0$ & 2 & 99 & & 42.6 & & 1.59 \\
\hline 12 & PDDL & $100 / 1 / 1 / 0$ & 2 & 99 & & 24.3 & & 1.73 \\
\hline
\end{tabular}

${ }^{a}$ Polymerizations were performed in toluene under $\mathrm{Ar}$ at $80{ }^{\circ} \mathrm{C}$. The initial molar ratio of $[\mathrm{ML}]_{0}:[\mathrm{SL}]_{0}$ was $100: 100 .{ }^{b}$ Conversion was determined by $500 \mathrm{MHz}{ }^{1} \mathrm{H}$ NMR spectra of crude product from the integral of $\omega$-methylene protons of MLs, SLs, and (co)polymers in CDCl ${ }^{c}{ }^{c}$ Determined by $950 \mathrm{MHz}{ }^{1} \mathrm{H}$ NMR spectra of methylene protons from $\mathrm{BnOH}$ and $\omega$-methylene protons of PMLs- $b$-PSLs in CDCl ${ }_{3}{ }^{d}$ Determined by HT-GPC in $\mathrm{TCB}$ at $150{ }^{\circ} \mathrm{C}$ (polystyrene standards). ${ }^{e}$ The initial molar ratio of $[\mathrm{PDL}]_{0}:[\mathrm{CL}]_{0}$ was 50:400.

propagation in the presence of $t-\mathrm{BuP}_{4}$ as a single catalyst. Thus, synthesis of PMLs- $b$-SLs by one-pot sequential monomer addition with $t$ - $\mathrm{BuP}_{4}$ as single catalyst was not successful. The same case was also observed when $\mathrm{Mg}(\mathrm{BHT})_{2}(\mathrm{THF})_{2},{ }^{25} \mathrm{Al}-$ salen complex, ${ }^{14}$ enzyme CAL-B, ${ }^{23}$ and $\mathrm{TBD}^{18}$ were used as catalysts.

In order to tackle the aforementioned challenge, we carried out sequential block copolymerization of MLs and SLs by employing catalyst-switch strategy after the ROP of MLs promoted by $t$ - $\mathrm{BuP}_{4}$. As mentioned in the Introduction, this strategy can be applied either by adding an excess of an acid (e.g., DPP) to neutralize the $t$ - $\mathrm{BuP}_{4}$ and to act as catalyst for the second, sensitive to $t-\mathrm{BuP}_{4}, \mathrm{SL}$ monomer ${ }^{29-31}$ (e.g., CL) or by adding a stoichiometric to the superbase, acid amount, followed by addition of a more suitable catalyst $\left(t-\mathrm{BuP}_{2}\right)$ to promote the ROP of SLs (Scheme 1). ${ }^{32}$ We have chosen the second methodology for the following two reasons: (a) the ROP of SLs in the presence of DPP at $80{ }^{\circ} \mathrm{C}$, where the PML macroinitiators are soluble, was not controllable (Scheme S1 and Figure S1, Supporting Information) and (b) unlike $t$ - $\mathrm{BuP}_{2}$, DPP is not a good catalyst for the ROP of L-lactide (LLA), which is limiting the generality of our strategy. ${ }^{30}$ Therefore, the catalyst-switch methodology from $t-\mathrm{BuP}_{4}$ to $\mathrm{DPP}$ was not employed in this work.

Then, ROP of PDL was performed with $\mathrm{BnOH}: t-\mathrm{BuP}_{4}: \mathrm{PDL}$ molar ratio of $1: 1: 100$ in toluene at $80{ }^{\circ} \mathrm{C}$ (entry 3, Table 1 ), followed by addition of an equivalent to $t$ - $\mathrm{BuP}_{4}$ amount of DPP and stirring. After $30 \mathrm{~min}, t-\mathrm{BuP}_{2}(5 \mathrm{~mol}$ equiv to $\mathrm{BnOH})$ was added, and the the solution was left under stirring was continued for $30 \mathrm{~min}$ to activate the PPDL chain end, followed by addition of CL. The reaction was continued for 4 days, and the progress of the reaction was monitored by ${ }^{13} \mathrm{C} \mathrm{NMR}$ 
spectroscopy (Figure 1, right). In contrast to the previous experiment with sequential addition of monomer, the ROP of $\mathrm{CL}$ at $80{ }^{\circ} \mathrm{C}$ proceeded without any randomization of the polymer sequencing. ${ }^{13} \mathrm{C}$ NMR spectra showed only a new linkage coming from $\mathrm{CL}^{*}-\mathrm{CL}$, while the linkage of PDL*PDL remained intact. The existence of $\mathrm{CL}^{*}-\mathrm{CL}$ and PDL*PDL dyads of carbonyl carbons is a strong evidence for the formation of PPDL- $b$-PCL. ${ }^{14}$ The carbonyl carbons peaks of this PPDL- $b$-PCL (entry 1, Table 3 ) are comparable to the blend of PPDL:PCL homopolymers peaks (Figure S2).

${ }^{1} \mathrm{H}$ NMR spectroscopy was also used to characterize the copolymers of Table 1 . A full ${ }^{1} \mathrm{H}$ NMR spectrum of PPDL-CL copolymer as well as the characteristic peaks $\alpha$ and $\omega$ methylene protons of copolymers prepared by sequential (entry 1), one-shot monomer addition (entry 2), and catalystswitch strategy (entry 3 ) are presented in Figure 2. As expected, no difference could be seen in shape and position among the $\alpha$ and $\omega$ methylene protons peaks of random and block copolymers of PPDL-PCL (entries 1-3). Multiplet peaks appear between 4.02 and 4.04 ppm coming from the overlapping of $\alpha$-methylene protons of PDL and CL $(\mathrm{a}+\mathrm{i})$. $\omega$-Methylene protons of PDL (b) and CL (f) appear as triplettriplet in the chemical shift around 2.23-2.28 ppm. The rest of the $\mathrm{CH}_{2}$ protons of PPDL and PCL appear in the range of $1.22-1.64 \mathrm{ppm}$ (c, d, e, g, and h). It is worth noting that $\omega$ methylene protons of PMLs and PCL recorded by the 500 $\mathrm{MHz}{ }^{1} \mathrm{H}$ NMR spectrometer are observed as overlapped peaks, while $\omega$-methylene protons of PMLs and PVL are well separated. $^{25}$ Therefore, we used the $950 \mathrm{MHz}$ NMR spectrometer which has higher resolution to resolve the peaks position and allowing quantitative calculation of the block copolymer composition.

Seven block copolymers from the combination of MLs (PDL, HDL, and DDL) and SLs (VL and CL) were prepared by the catalyst-switch strategy. All PMLs-b-PSLs (runs 1-7, Table 2) as well as the corresponding PMLs and PSLs homopolymers (runs $8-12$, Table 2) were prepared in toluene at $80{ }^{\circ} \mathrm{C}$. The conversion of monomers in each block copolymerization reaches high conversion, indicating the capability of $t$ - $\mathrm{BuP}_{4}$ and $t$ - $\mathrm{BuP}_{2}$ employed in this system to promote ROP of MLs and SLs, respectively. The conversion of MLs to PMLs was determined by ${ }^{1} \mathrm{H}$ NMR from the integral of $\alpha$-methylene protons of PMLs and those of MLs ( $\mathrm{a}$ and $\mathrm{a}^{\prime}$, Figure S3). The conversion of PSLs to PMLs-b-PSLs was determined from the integral of $\omega$-methylene protons of PSLs and those of SLs ( $f$ and $\mathrm{f}^{\prime}$, Figure S4).

${ }^{1} \mathrm{H}$ and ${ }^{13} \mathrm{C}$ NMR spectra of the isolated block copolymers (entries 1-7, Table 2) are presented in Figure S5-S18. Since the $\omega$-methylene protons of PMLs and PSLs in the resulting block copolymers could be observed at different chemical shift by the $950 \mathrm{MHz}$ NMR spectrometer, accurate determination of block length and $M_{n}$ of PML- $b$-PSL was possible. The length of each block was determined from the integral ratio of methylene protons of initiator $(\mathrm{BnOH})$ at $5.10 \mathrm{ppm}$ to that of the $\omega$ methylene protons of PMLs $(\sim 2.27 \mathrm{ppm})$ and PSLs $(\sim 2.24$ ppm). ROP of MLs in the presence of $t-\mathrm{BuP}_{4}$ reached high conversion in $2 \mathrm{~h}$. In contrast, the ROP of SLs from PMLs macroinitiator ( $\geq 96 \mathrm{~h}$ ) was slower than the homopolymerization of SLs from $\mathrm{BnOH}$ initiator $(\sim 48 \mathrm{~h})$ under the same reaction conditions likely because of a retardation effect due to the organic salt (phosphazenium diphenylphosphate) generated by the neutralization of $t-\mathrm{BuP}_{4}$ with $\mathrm{DPP} .^{30,34}$
HT-GPC was used to monitor the molecular weight and the $\bigoplus_{\mathrm{M}}$ of PPDL and PPDL- $b$-PCL (entry 1, Table 2). The ROP of $\mathrm{PDL}$ catalyzed by $t$ - $\mathrm{BuP}_{4}$ gives homopolymer with monomodal distribution (blue line, Figure 3). After switching the catalyst to

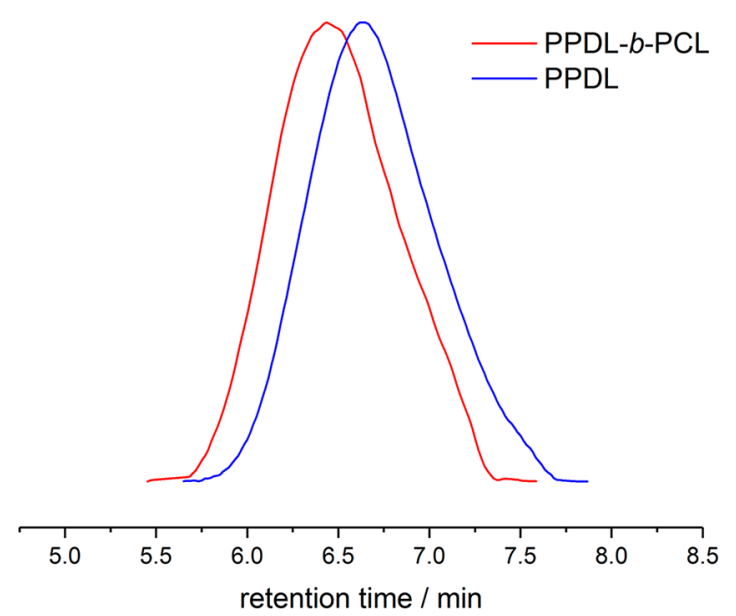

Figure 3. HT-GPC traces of PPDL (blue) macroinitiator and PPDL-bPCL (red) prepared by catalyst-switch strategy (TCB, $150{ }^{\circ} \mathrm{C}$, PS standards).

$t$ - $\mathrm{BuP}_{2}, \mathrm{CL}$ monomer was added and polymerized for 4 days. The HT-GPC trace of the isolated product clearly shows the increase in molecular weight with the appearance of a monomodal peak at higher molecular weight region (red line, Figure 3), indicating that the formation of block copolymer initiated from PPDL. The monomodal and symmetrical GPC traces of PPDL- $b$-PCL imply that minimum transesterification occurred during the chain propagation of $\mathrm{CL}$ from PPDL macroinitiator in the presence of $t$ - $\mathrm{BuP}_{2}$. HT-GPC traces of the rest of block copolymers (entries 2-7, Table 2), showing the increase of molecular weight from PMLs to PMLs-b-PSLs, are given in Figures S19-S24.

The relatively broad $\bigoplus_{M}$ of PMLs- $b$-PSLs (entries $1-7$, Table 2) is attributed to the broad $\bigoplus_{M}$ of the first PML block, caused by transesterification reactions during the ROP of the ML monomer. ${ }^{21}$ On the contrary, intermolecular transesterification reaction is negligible for the ROP of SLs (entries 8 and 9, Table 2) with $t-\mathrm{BuP}_{2}$ leading to the formation of PSLs with narrow $\bigoplus_{\mathrm{M}}$.

With the literature showing a complex phase behavior for block copolymers, ${ }^{35-39}$ it was essential to ascertain the thermal properties to understand the phase behavior of PMLs- $b$-PSLs block copolymers. The $T_{\mathcal{c}}, T_{\mathrm{m}}$, and melting enthalpy $\left(\Delta H_{\mathrm{m}}\right)$ of each component were determined using DSC. As seen in Figure 4 and Table 3, all block copolymers show a distinct crystallization $\left(62{ }^{\circ} \mathrm{C}<T_{\mathrm{c}, \mathrm{PML}}<75{ }^{\circ} \mathrm{C}\right)$ and corresponding melting peak $\left(85{ }^{\circ} \mathrm{C}<T_{\mathrm{m} \text {,PML }}<95{ }^{\circ} \mathrm{C}\right)$ for the PML component and a smaller crystallization $\left(38{ }^{\circ} \mathrm{C}<T_{\mathrm{c}, \mathrm{PSL}}<47\right.$ $\left.{ }^{\circ} \mathrm{C}\right)$ and corresponding melting peak $\left(53{ }^{\circ} \mathrm{C}<T_{\mathrm{m}, \mathrm{PSL}}<59^{\circ} \mathrm{C}\right)$ for PSL, which indicates the sequential crystallization of the PML component followed by the PSL component. Despite PML constituting a majority of the block copolymer, a noticeable decrease in $T_{\mathrm{c} \text { PML }}$ relative to PML-homopolymer $\left(\Delta T_{\mathrm{c}, \mathrm{PML}}>3.8^{\circ} \mathrm{C}\right)$ was observed. This behavior is consistent with crystallization of PML from mixed/partially mixed melt phase, expected from the chemical similarity between PMLs and PSLs. Despite a reduction in $T_{\mathrm{c}, \mathrm{PML}}$, little to no deviations in $T_{\mathrm{m}, \mathrm{PML}}\left(\Delta T_{\mathrm{c}, \mathrm{PML}}<3{ }^{\circ} \mathrm{C}\right)$ was observed, indicating the 

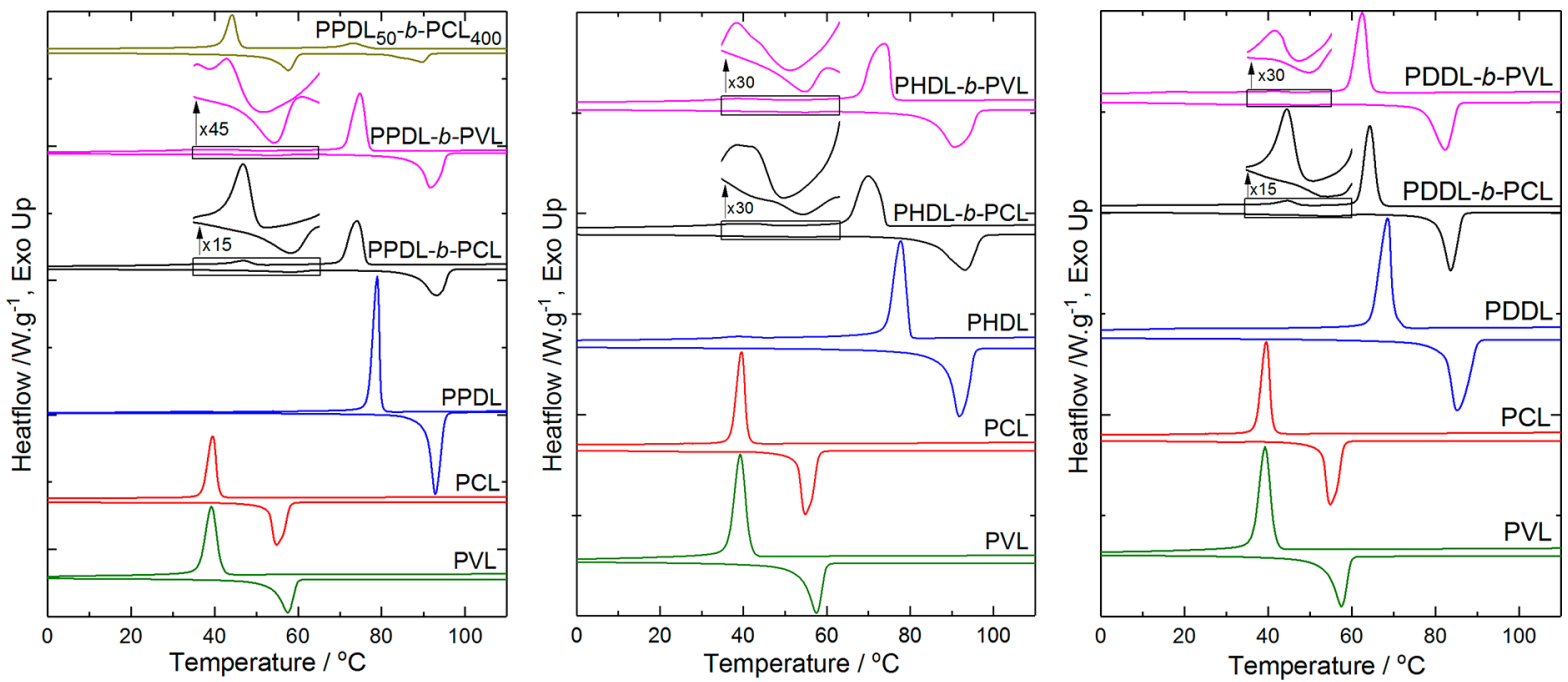

Figure 4. DSC traces of PPDL (left), PHDL (middle), and PDDL (right) based block copolymers with SLs (catalyst-switch) and the corresponding homopolymers (under air, $10{ }^{\circ} \mathrm{C} \mathrm{min}^{-1}$ ).

Table 3. Physical Properties of PMLs-b-PSLs Prepared by Catalyst-Switch Strategy

\begin{tabular}{|c|c|c|c|c|c|c|c|c|c|c|}
\hline \multirow[b]{2}{*}{ entry } & \multirow[b]{2}{*}{ sample } & \multicolumn{2}{|c|}{$F^{a}$} & \multicolumn{2}{|c|}{$T_{\mathrm{c}}^{b}\left({ }^{\circ} \mathrm{C}\right)$} & \multicolumn{2}{|c|}{$T_{\mathrm{m}}{ }^{b}\left({ }^{\circ} \mathrm{C}\right)$} & \multirow[b]{2}{*}{$\Delta H_{\mathrm{m}, \mathrm{PML}}{ }^{b}\left(\mathrm{~J} \mathrm{~g}^{-1}\right)$} & \multirow[b]{2}{*}{$\Delta H_{\mathrm{m}, \mathrm{PSL}}{ }^{b}\left(\mathrm{~J} \mathrm{~g}^{-1}\right)$} & \multirow[b]{2}{*}{$X_{c}^{c}(\%)$} \\
\hline & & PML & PSL & PML & PSL & PML & PSL & & & \\
\hline 1 & PPDL- $b$-PCL & 0.69 & 0.31 & 74.2 & 46.9 & 93.3 & 57.9 & -77.9 & -9.74 & 55.0 \\
\hline 2 & PPDL- $b$-PVL & 0.75 & 0.25 & 74.8 & 43.1 & 91.8 & 58.8 & -96.5 & -5.98 & 51.8 \\
\hline 3 & PHDL- $b$-PCL & 0.75 & 0.25 & 74.0 & 38.4 & 93.2 & 53.6 & -91.3 & -5.20 & 54.7 \\
\hline 4 & PHDL-b-PVL & 0.79 & 0.21 & 70.2 & 40.7 & 91.0 & 54.3 & -101.3 & -3.11 & 54.2 \\
\hline 5 & PDDL- $b$-PCL & 0.63 & 0.37 & 64.3 & 44.7 & 83.1 & 55.0 & -77.1 & -8.82 & 48.8 \\
\hline 6 & PDDL- $b$-PVL & 0.67 & 0.33 & 62.4 & 42.3 & 82.3 & 55.6 & -82.2 & -9.46 & 45.8 \\
\hline 7 & $\mathrm{PPDL}_{50}-b-\mathrm{PCL}_{400}$ & 0.22 & 0.78 & 73.2 & 44.2 & 89.8 & 57.8 & -22.9 & -43.0 & 55.6 \\
\hline 8 & PCL & & 1 & & 39.5 & & 54.8 & & -77.7 & 62.7 \\
\hline 9 & PVL & & 1 & & 39.5 & & & 57.4 & -72.5 & 61.1 \\
\hline 10 & PPDL & 1 & & 79.0 & & 92.9 & & -129.0 & & 63.1 \\
\hline 11 & PHDL & 1 & & 77.8 & & 91.9 & & -120.5 & & 57.5 \\
\hline 12 & PDDL & 1 & & 68.6 & & 85.3 & & -125.5 & & 60.0 \\
\hline
\end{tabular}

${ }^{a}$ Mass fraction of each block based on the molecular weight determined by $950 \mathrm{MHz}{ }^{1} \mathrm{H}$ NMR spectra from integral ratio of methylene protons $\mathrm{BnOH}$ and $\omega$-methylene protons of PMLs and PSLs $\left(\mathrm{CDCl}_{3}, \mathrm{rt}\right) .{ }^{b}$ Measured by DSC under air with heating rate $10^{\circ} \mathrm{C}$ min ${ }^{-1}$. ${ }^{c}$ Determined by XRD with formula $X_{c}=\operatorname{area}_{\text {crystalline }} /$ area $_{\text {total }}$ in XRD spectra.

presence of amorphous PSL phase only affected the kinetics of crystallization and not the size of the crystal stacks of the PML component. At temperature below $T_{c, \mathrm{PML}}$, the crystallization of PSL is observed. Contrary to the deviations observed in $T_{c, P M L}$ the crystallization of PSL shows either the same (observed for PHDL- $b$-PCL and PHDL- $b$-PVL, $<1.2{ }^{\circ} \mathrm{C}$ ) or an increase (observed for PPDL- $b$-PCL, PPDL- $b$-PVL, PDDL- $b$-PCL, and PDDL- $b$-PVL, $>2.8{ }^{\circ} \mathrm{C}$ ) in $T_{c, P S L}$ relative to the PSL homopolymer. It is evident that the PML crystals act as nucleating agents for the PSL component despite imposing spatial confinement on the PSL crystallization. $T_{\mathrm{m}, \mathrm{PSL}}$ shows subtle deviations from the PSL homopolymers $\left(<3.1{ }^{\circ} \mathrm{C}\right)$, similar to $T_{\mathrm{m}, \mathrm{PML}}$ indicating the PSL crystal stack size was relatively unperturbed from the presence PML crystals.

Although DSC traces (Figure 4) show expected peaks for both PML and PSL, the $\Delta H_{\mathrm{m}}$ (Table 3), normalized by the corresponding mass fraction $(F)$, shows a substantial decrease in $\Delta H_{\mathrm{m}, \mathrm{PSL}}$ (around $60 \%$ ) with a relatively unchanged $\Delta H_{\mathrm{m}, \mathrm{PML}}$ (reduction of roughly 10\%) compared to the corresponding homopolymers. For example, in PPDL- $b$-PCL, $F_{\mathrm{PPDL}}=0.69$ and $F_{\mathrm{PCL}}=0.31$ with $\Delta H_{\mathrm{m}, \mathrm{PPDL}}=-77.9 \mathrm{~J} \mathrm{~g}^{-1}$ and $\Delta H_{\mathrm{m}, \mathrm{PCL}}=$ $-9.74 \mathrm{~J} \mathrm{~g}^{-1}$. After normalization, the heats become $\Delta H_{\mathrm{m}, \mathrm{PPDL}}=$
$-112.9 \mathrm{~J} \mathrm{~g}^{-1}$ PPDL and $\Delta H_{\mathrm{m}, \mathrm{PPDL}}=-31.4 \mathrm{~J} \mathrm{~g}^{-1}$ PCL showing a $12 \%$ and $60 \%$ reduction for PML and PSL component, respectively. This surprising reduction in $\Delta H_{\mathrm{m}, \mathrm{PSL}}$ was observed in all block copolymer samples, which puts into question the successful synthesis of block copolymers. Double-semicrystalline random copolymers have a characteristic single-crystallization behavior, and blends with short PSL components may lead to kinetic trapping of PSL chain during the crystallization of PML, which may also exhibit a near-single-crystalline behavior. ${ }^{40}$ Thus, additional experiments were done to eliminate the possibilities that could lead to this puzzling near-single-phase transition result to validate the successful synthesis of block copolymers. The random copolymers PPDL$r$-PCL (Table 1, entries 1 and 2) were analyzed by DSC. The DSC traces (Figure 5) are juxtaposed with PPDL-b-PCL block copolymers (Table 1 , entry 3 ). Indeed, the random copolymers show a single peak, but at temperatures much lower than that was observed for the block copolymer. Next, blends with matching composition to the $F$ of each block copolymers in Table 2 were prepared (Table S1). The DSC traces of blends showed drastic differences compared to block copolymers in the number, size, shape, and position of peaks (Table S1 and 


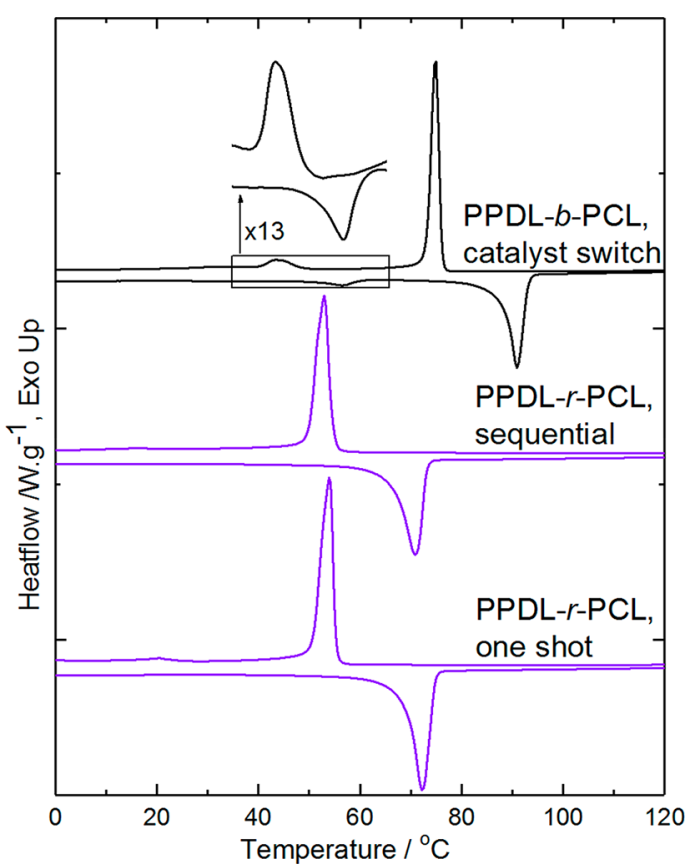

Figure 5. DSC traces of copolymers in Table 1: PPDL-r-PCL (oneshot, $t$-BuP 4 ), PPDL- $r$-PCL (sequential, $t$-BuP $_{4}$ ), and PPDL- $b$-PCL (catalyst-switch) (under air, $10{ }^{\circ} \mathrm{C} \mathrm{min}^{-1}$ ).

Figures S25-S31). The differences show the near singlecrystalline behavior cannot be explained by random copolymerization nor the formation of blends.

Finally, we verify the possibility of the small $\Delta H_{\mathrm{m}, \mathrm{PSL}}$ resulting from block copolymers through prior work in the literature and additional synthesis with different $F$. Literature $^{40,41}$ shows that for double-semicrystalline block copolymers the crystallization and melting of the lower melting component could be completely suppressed by the block copolymer arrangement at low $F$, similar molecular properties as PMLs-b-PSLs samples. The small $\Delta H_{\mathrm{m}, \mathrm{PSL}}$ result is consistent with block copolymers with a minor low melting temperature component. To further verify our claims, a block copolymer was synthesized with a major PSL and minor PML component, $\mathrm{PPDL}_{50}-b$ - $\mathrm{PCL}_{400}$ (entry 7 , Table 2). As can be seen in Figure 4 (left), two distinct crystallization and melting peaks are observed: $\Delta H_{\mathrm{m}, \mathrm{PPDL}}=22.9 \mathrm{~J} \mathrm{~g}^{-1}$ and $\Delta H_{\mathrm{m}, \mathrm{PCL}}=43.0$ $\mathrm{J} \mathrm{g}^{-1}$ (Table 3). After normalization by the $F$ value of each block, $\Delta \hat{H}_{\mathrm{m}, \mathrm{PPDL}}=104.1 \mathrm{~J} \mathrm{~g}^{-1}(\mathrm{PPDL})$ and $\Delta \hat{H}_{\mathrm{m}, \mathrm{PCL}}=55 \mathrm{~J} \mathrm{~g}^{-1}$ (PCL), verifying the presence of both PPDL and PCL blocks in the polymer. Thus, the DSC results $\left(T_{\mathcal{c}} T_{\mathrm{m}}\right.$, and $\left.\Delta H_{\mathrm{m}}\right)$ also corroborate the formation of PMLs- $b$-PSLs.

The crystal structure was analyzed using XRD. The samples were heated to $120{ }^{\circ} \mathrm{C}$ (above $T_{\mathrm{m}}$ of both components) and cooled to ambient condition at roughly $10{ }^{\circ} \mathrm{C} \mathrm{min}^{-1}$. All samples showed peaks at around $2 \theta=21.5^{\circ}$ and $24^{\circ}$ (Figure 6 and Table S2), characteristic of diffraction from (110) and (200) crystallographic planes, respectively. These crystallographic planes represent orthorhombic crystal structure, consistent with prior work in PSLs and PMLs in the literature. $^{14,25}$ Thus, the successful synthesis of PMLs and PSLs is supported by XRD results.

Slight differences in peak positions are observed due to the differences in distances in the ester group along the backbone (Figure 6 and Table S2). Most block copolymer samples resemble the diffraction pattern of the PML homopolymer, suggesting the phase behavior of the block copolymer is controlled primarily by the PML component. This behavior is expected due to the PML component (1) crystallizing first (higher $T_{\mathrm{m}}$ than PSL) and (2) constituting the majority of the block copolymer. PPDL- $b$-PVL and PDDL- $b$-PCL block copolymers did not show this behavior, but understanding the origin of the deviation is beyond the scope of this work and will not be discussed.

The degree of crystallinity, $X_{\mathcal{c}}$ was taken to be the ratio of the area of the crystalline peaks to the amorphous halo. As can be seen in Table 3, lower $X_{c}$ values are observed for the block copolymers $\left(0.46<X_{c}<0.56\right)$ than all homopolymers $(0.58<$ $X_{c}<0.63$ ), indicating that the total crystalline composition of the block copolymers is less than the homopolymers. This result is in agreement with DSC results (Figure 4 and Table 3 ) which showed $\Delta H_{\mathrm{m}, \mathrm{PML}}$ and $\Delta H_{\mathrm{m}, \mathrm{PSL}}$ of block copolymers having values smaller than the corresponding PML and PSL homopolymers.

\section{CONCLUSION}

Conventional block copolymerization by sequential addition of MLs and SLs with $t$ - $\mathrm{BuP}_{4}$ as catalyst produces random microstructure due to rapid transesterification side reactions.
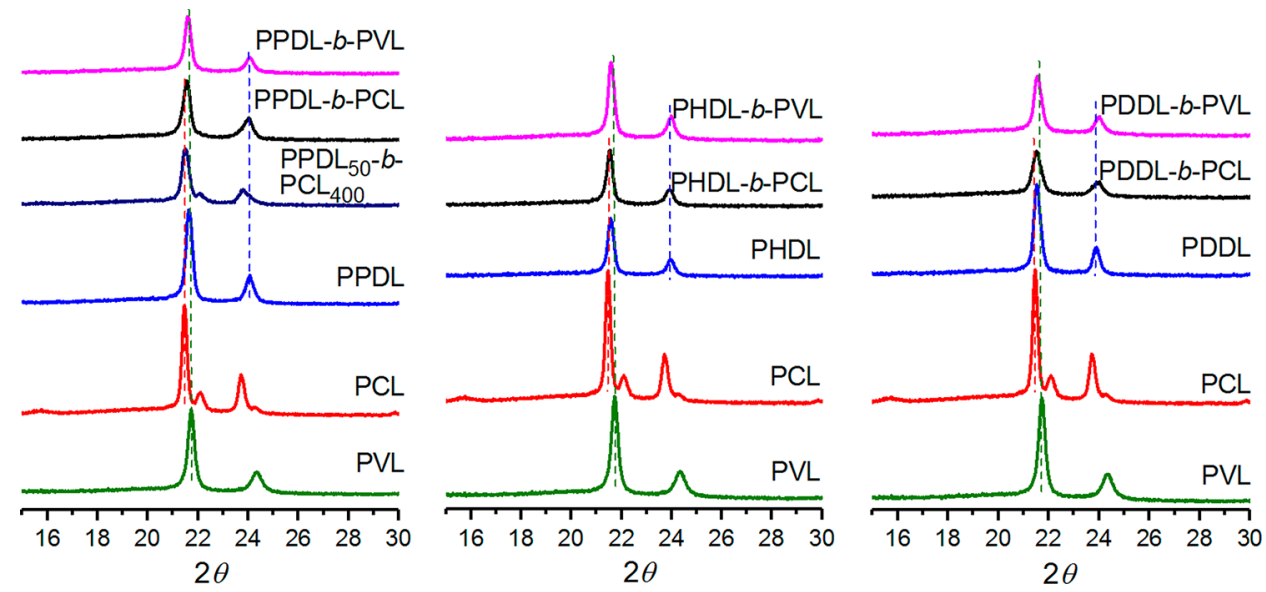

Figure 6. XRD diffractograms of PPDL (left), PHDL (middle), and PDDL (right) based block copolymers (catalyst-swicth) with PSLs and the corresponding homopolymers. 
In contrast, a catalyst-switch strategy that employs two different PSBs, $t-\mathrm{BuP}_{4}$ for MLs and $t-\mathrm{BuP}_{2}$ for SLs, led to the successful synthesis of PMLs- $b$-PSLs. ${ }^{13} \mathrm{C}$ and ${ }^{1} \mathrm{H}$ NMR spectroscopies as well as HT-GPC confirm the formation of block copolymers. DSC and XRD studies show that the thermal properties and phase behavior of PMLs- $b$-PSLs are largely influenced by PMLs block if PMLs components constitute the majority of the block copolymers. Since $t$ - $\mathrm{BuP}_{2}$ is also a powerful catalyst for the ROP of cyclic monomers such as lactides and cyclic carbonates, this method opens many possibilities for the synthesis of new multiblock polymers, e.g., PML- $b$-PSL- $b$-polycarbonate- $b$-polylactide.

\section{ASSOCIATED CONTENT}

\section{S Supporting Information}

The Supporting Information is available free of charge on the ACS Publications website at DOI: 10.1021/acs.macromol.8b00153.

Scheme S1, Figures S1-S31 (NMR, GPC, and DSC results), and Tables $\mathrm{S} 1$ and $\mathrm{S} 2$ (PDF)

\section{AUTHOR INFORMATION}

\section{Corresponding Author}

*(N.H.) Tel + 966-(0)12-8080789; e-mail nikolaos. hadjichristidis@kaust.edu.sa.

\section{ORCID}

Panayiotis Bilalis: 0000-0002-5809-9643

Yves Gnanou: 0000-0001-6253-7856

Nikos Hadjichristidis: 0000-0003-1442-1714

\section{Present Address}

${ }^{\S}$ Department of Chemical Engineering, CALTECH, Pasadena, California 91125, United States.

\section{Notes}

The authors declare no competing financial interest.

\section{ACKNOWLEDGMENTS}

Research was supported by King Abdullah University of Science and Technology (KAUST).

\section{REFERENCES}

(1) Rabnawaz, M.; Wyman, I.; Auras, R.; Cheng, S. A roadmap towards green packaging: the current status and future outlook for polyesters in the packaging industry. Green Chem. 2017, 19 (20), $4737-4753$

(2) Spizzirri, U. G.; Cirillo, G.; Iemma, F. Polymers and Food Packaging: A Short Overview. In Functional Polymers in Food Science; John Wiley \& Sons, Inc.: 2015; pp 1-8.

(3) Barouti, G.; Jaffredo, C. G.; Guillaume, S. M. Advances in drug delivery systems based on synthetic poly(hydroxybutyrate) (co)polymers. Prog. Polym. Sci. 2017, 73, 1-31.

(4) Hajiali, F.; Tajbakhsh, S.; Shojaei, A. Fabrication and Properties of Polycaprolactone Composites Containing Calcium PhosphateBased Ceramics and Bioactive Glasses in Bone Tissue Engineering: A Review. Polym. Rev. 2018, 58, 164-207.

(5) Winnacker, M. Covalent polyester-biomolecule conjugates: advances in their synthesis and applications in biomedicine and nanotechnology. Polym. Int. 2017, 66, 1747-1755.

(6) Sinclair, R. G. The case for polylactic acid as a commodity packaging plastic. J. Macromol. Sci., Part A: Pure Appl.Chem. 1996, 33 (5), 585-597.

(7) Mobley, D. P. Plastics from Microbes; Hanser Publisher: Munich, Germany, 1994.
(8) Vilela, C.; Sousa, A. F.; Fonseca, A. C.; Serra, A. C.; Coelho, J. F. J.; Freire, C. S. R.; Silvestre, A. J. D. The quest for sustainable polyesters - insights into the future. Polym. Chem. 2014, 5 (9), 31193141.

(9) Zia, K. M.; Noreen, A.; Zuber, M.; Tabasum, S.; Mujahid, M. Recent developments and future prospects on bio-based polyesters derived from renewable resources: A review. Int. J. Biol. Macromol. 2016, 82, 1028-1040.

(10) Lecomte, P.; Jerome, C. Recent Developments in Ring-Opening Polymerization of Lactones. In Synthetic Biodegradable Polymers; Rieger, B., Kunkel, A., Coates, G. W., Reichardt, R., Dinjus, E., Zevaco, T. A., Eds.; Springer: Berlin, 2012; Vol. 245, pp 173-217.

(11) Duda, A.; Penczek, S. Aliphatic Polyester Formation, Mechanisms of. In Biopolymers Online; Wiley-VCH Verlag GmbH \& Co. KGaA: 2005.

(12) Alamri, H.; Zhao, J.; Pahovnik, D.; Hadjichristidis, N. Phosphazene-catalyzed ring-opening polymerization of epsilon-caprolactone: influence of solvents and initiators. Polym. Chem. 2014, 5 (18), 5471-5478.

(13) Lofgren, A.; Albertsson, A. C.; Dubois, P.; Jerome, R. Recent advances in ring-opening polymerization of lactones and relatedcompounds. J. Macromol. Sci., Polym. Rev. 1995, 35 (3), 379-418.

(14) Bouyahyi, M.; Duchateau, R. Metal-Based Catalysts for Controlled Ring-Opening Polymerization of Macrolactones: High Molecular Weight and Well-Defined Copolymer Architectures. Macromolecules 2014, 47 (2), 517-524.

(15) Pepels, M. P. F.; Bouyahyi, M.; Heise, A.; Duchateau, R. Kinetic Investigation on the Catalytic Ring-Opening (Co)Polymerization of (Macro)Lactones Using Aluminum Salen Catalysts. Macromolecules 2013, 46 (11), 4324-4334.

(16) van der Meulen, I.; Gubbels, E.; Huijser, S.; Sablong, R.; Koning, C. E.; Heise, A.; Duchateau, R. Catalytic Ring-Opening Polymerization of Renewable Macrolactones to High Molecular Weight Polyethylenelike Polymers. Macromolecules 2011, 44 (11), 4301-4305.

(17) Myers, D.; Witt, T.; Cyriac, A.; Bown, M.; Mecking, S.; Williams, C. K. Ring opening polymerization of macrolactones: high conversions and activities using an yttrium catalyst. Polym. Chem. 2017, 8 (37), 5780-5785.

(18) Bouyahyi, M.; Pepels, M. P. F.; Heise, A.; Duchateau, R. omegaPentandecalactone Polymerization and omega-Pentadecalactone/ epsilon-Caprolactone Copolymerization Reactions Using Organic Catalysts. Macromolecules 2012, 45 (8), 3356-3366.

(19) Pascual, A.; Leiza, J. R.; Mecerreyes, D. Acid catalyzed polymerization of macrolactones in bulk and aqueous miniemulsion: Ring opening vs. condensation. Eur. Polym. J. 2013, 49 (6), 16011609.

(20) Pascual, A.; Sardon, H.; Veloso, A.; Ruipérez, F.; Mecerreyes, D. Organocatalyzed Synthesis of Aliphatic Polyesters from Ethylene Brassylate: A Cheap and Renewable Macrolactone. ACS Macro Lett. 2014, 3 (9), 849-853.

(21) Ladelta, V.; Bilalis, P.; Gnanou, Y.; Hadjichristidis, N. Ringopening polymerization of [small omega]-pentadecalactone catalyzed by phosphazene superbases. Polym. Chem. 2017, 8 (3), 511-515.

(22) Bisht, K. S.; Henderson, L. A.; Gross, R. A.; Kaplan, D. L.; Swift, G. Enzyme-Catalyzed Ring-Opening Polymerization of $\omega$-Pentadecalactone. Macromolecules 1997, 30 (9), 2705-2711.

(23) Kumar, A.; Kalra, B.; Dekhterman, A.; Gross, R. A. Efficient Ring-Opening Polymerization and Copolymerization of $\varepsilon$-Caprolactone and $\omega$-Pentadecalactone Catalyzed by Candida antartica Lipase B. Macromolecules 2000, 33 (17), 6303-6309.

(24) Pepels, M. P. F.; Koeken, R. A. C.; van der Linden, S. J. J.; Heise, A.; Duchateau, R. Mimicking (Linear) Low-Density Polyethylenes Using Modified Polymacrolactones. Macromolecules 2015, 48 (14), 4779-4792.

(25) Wilson, J. A.; Hopkins, S. A.; Wright, P. M.; Dove, A. P. Synthesis of $\omega$-Pentadecalactone Copolymers with Independently Tunable Thermal and Degradation Behavior. Macromolecules 2015, 48 (4), 950-958. 
(26) Walther, P.; Naumann, S. N-Heterocyclic Olefin-Based (Co)polymerization of a Challenging Monomer: Homopolymerization of $\omega$-Pentadecalactone and Its Copolymers with $\gamma$-Butyrolactone, $\delta$ Valerolactone, and $\varepsilon$-Caprolactone. Macromolecules 2017, 50 (21), 8406-8416.

(27) Jasinska-Walc, L.; Bouyahyi, M.; Rozanski, A.; Graf, R.; Hansen, M. R.; Duchateau, R. Synthetic Principles Determining Local Organization of Copolyesters Prepared from Lactones and Macrolactones. Macromolecules 2015, 48 (3), 502-510.

(28) Zhao, J.; Hadjichristidis, N. Polymerization of 5-alkyl deltalactones catalyzed by diphenyl phosphate and their sequential organocatalytic polymerization with monosubstituted epoxides. Polym. Chem. 2015, 6 (14), 2659-2668.

(29) Zhao, J.; Pahovnik, D.; Gnanou, Y.; Hadjichristidis, N. One-Pot Synthesis of Linear- and Three-Arm Star-Tetrablock Quarterpolymers via Sequential Metal-Free Ring-Opening Polymerization Using a "Catalyst Switch" Strategy. J. Polym. Sci., Part A: Polym. Chem. 2015, 53 (2), 304-312.

(30) Zhao, J.; Pahovnik, D.; Gnanou, Y.; Hadjichristidis, N. A "Catalyst Switch" Strategy for the Sequential Metal-Free Polymerization of Epoxides and Cyclic Esters/Carbonate. Macromolecules 2014, 47 (12), 3814-3822.

(31) Zhao, J.; Pahovnik, D.; Gnanou, Y.; Hadjichristidis, N. Sequential polymerization of ethylene oxide, epsilon-caprolactone and L-lactide: a one-pot metal-free route to tri-and pentablock terpolymers. Polym. Chem. 2014, 5 (12), 3750-3753.

(32) Alamri, H.; Hadjichristidis, N. One-pot synthesis of well-defined polyether/polyester block copolymers and terpolymers by a highly efficient catalyst switch approach. Polym. Chem. 2016, 7 (19), 32253228.

(33) Theodosopoulos, G.; Pitsikalis, M. Block Copolymers by Anionic Polymerization: Recent Synthetic Routes and Developments. In Anionic Polymerization: Principles, Practice, Strength, Consequences and Applications; Hadjichristidis, N., Hirao, A., Eds.; Springer Japan: Tokyo, 2015; pp 541-623.

(34) Xia, Y.; Chen, Y.; Song, Q.; Hu, S.; Zhao, J.; Zhang, G. Base-toBase Organocatalytic Approach for One-Pot Construction of Poly(ethylene oxide)-Based Macromolecular Structures. Macromolecules 2016, 49 (18), 6817-6825.

(35) Jiang, Q.; Ward, M. D. Crystallization under nanoscale confinement. Chem. Soc. Rev. 2014, 43 (7), 2066-2079.

(36) Li, S.; Register, R. A. Crystallization in Copolymers. In Handbook of Polymer Crystallization; John Wiley \& Sons, Inc.: 2013; pp 327-346.

(37) Michell, R. M.; Müller, A. J. Confined crystallization of polymeric materials. Prog. Polym. Sci. 2016, 54-55, 183-213.

(38) Nakagawa, S.; Marubayashi, H.; Nojima, S. Crystallization of polymer chains confined in nanodomains. Eur. Polym. J. 2015, 70, $262-275$.

(39) Xue, F.; Jiang, S. Crystallization Behaviors and Structure Transitions of Biocompatible and Biodegradable Diblock Copolymers. Polymers 2014, 6 (8), 2116.

(40) Gan, Z.; Jiang, B.; Zhang, J. Poly( $\varepsilon$-caprolactone)/poly(ethylene oxide) diblock copolymer. I. Isothermal crystallization and melting behavior. J. Appl. Polym. Sci. 1996, 59 (6), 961-967.

(41) Ghoroghchian, P. P.; Li, G.; Levine, D. H.; Davis, K. P.; Bates, F. S.; Hammer, D. A.; Therien, M. J. Bioresorbable Vesicles Formed through Spontaneous Self-Assembly of Amphiphilic Poly(ethylene oxide)-block-polycaprolactone. Macromolecules 2006, 39 (5), 16731675. 